\title{
Reference ranges of glycated hemoglobin (HbA1c) in capillary blood in the Spanish population
}

María Barroso ${ }^{\mathrm{a}, \mathrm{b}, \mathrm{c}}$, Jose Miguel Baena-Díez ${ }^{\mathrm{d}}$, Daniel Muñoz-Aguayo ${ }^{\mathrm{e}, \mathrm{f}}$, Jorge Luis Díaz ${ }^{\mathrm{a}, \mathrm{g}}$, Helmut Schrödere, ${ }^{\mathrm{e}}$, María Grau ${ }^{\mathrm{a}, \mathrm{h}, \mathrm{i}^{*}}$

${ }^{\text {a }}$ Cardiovascular Epidemiology and Genetics. IMIM - Hospital del Mar Medical Research Institute, Barcelona, Spain

${ }^{\mathrm{b}}$ Gornal Primary Care Centre, IDIAP Jordi Gol, Catalan Institute of Health (ICS),

L'Hospitalet de Llobregat, Spain

${ }^{\mathrm{c}} \mathrm{PhD}$ Programme in Methodology of Biomedical Research and Public Health, Department of Pediatrics, Obstetrics and Gynecology and Preventive Medicine, Autonomous University of Barcelona, Spain

d La Marina Primary Care Centre, IDIAP Jordi Gol, Catalan Institute of Health (ICS), Barcelona, Spain

${ }^{\mathrm{e}}$ Cardiovascular Risk and Nutrition, IMIM - Hospital del Mar Medical Research Institute, Barcelona, Spain

${ }^{\mathrm{f}}$ Consortium for Biomedical Research in Obesity and Nutrition (CIBERobn), Barcelona, Spain

g Teaching Unit of Preventive Medicine and Public Health Mar Health Park - Pompeu-Fabra University - Barcelona Public Health Agency, Spain

${ }^{\mathrm{h}}$ Consortium for Biomedical Research in Epidemiology and Public Health (CIBEResp), Spain

${ }^{\mathrm{i}}$ Department of Medicine, University of Barcelona, Spain

*Corresponding author at:

Cardiovascular Epidemiology and Genetics

IMIM - Hospital del Mar Medical Research Institute

Carrer Dr. Aiguader, 88

08003 Barcelona, Spain

Tel +34 933160800

Fax +34933160796

email:mgrau@imim.es

Keywords. Glycated Hemoglobin A, Point-of-Care Testing, Primary Health Care, Preventive Medicine, Public Health, Epidemiology 


\section{HIGHLIGHTS}

1. HbA1c increased gradually with age in Mediterranean population without diabetes.

2. Almost half of participants older than 65 years had prediabetes levels of HbAlc.

3. HbA1c reference values in Mediterranean population was similar to other cohorts. 


\section{Summary}

Cross-sectional analysis describing HbAlc reference values by sex and age in a randomly selected Mediterranean general population sample. Using two methods, Point-of-Care systems and centralized laboratory, results show that HbA1c values increase with age. Almost half of the sample aged 65 years or older had median values $>5.7 \%$ (prediabetes cutoff point).

\section{Introduction}

HbA1c level, a diagnostic test for diabetes, provides an accurate and reliable biomarker of mean 90-day blood glucose values, yielding highly reproducible results not only for diagnosis but also for follow-up monitoring of patients with diabetes [1]. The level of HbAlc is usually estimated in a central laboratory from venous blood sample. However, new techniques allow its measurement in capillary blood, obtained by pricking the pulp of the finger, and quick analysis with a Point of Care (POC) system [2, 3].

Mean $\mathrm{HbA1c}$ values and their association with cardiovascular risk factors have been analysed in differing geographic areas [4-6]. However, reference values of this biomarker in capillary blood have not been previously described in a general Mediterranean population. The objective of this study was to determine HbA1c levels by age group and sex in a Mediterranean population sample, using two different techniques: venous blood tested in a central laboratory and a capillary sample tested by a POC system. 


\section{Methods and results}

A randomized population-based cross-sectional study was conducted in adult residents of the city of Girona and surrounding areas (northeastern Spain), aged 35- 74 years with no history of diabetes or cardiovascular disease. Fasting biological samples (venous and capillary blood) were both collected on the same day. Methodology has been previously described [7].

Capillary blood analysis to determine $\mathrm{HbA} 1 \mathrm{c}$ was performed instantaneously with the Cobas b101 POC device, using latex agglutination procedures (Roche Diagnostics, Basel, Switzerland). This device meets the generally accepted performance criteria for HbA1c [8].

Venous samples were withdrawn in $<60$ seconds after $10-14 \mathrm{~h}$ fasting and stored at $-80^{\circ} \mathrm{C}$ for analysis within 6 months by a central laboratory. Glycaemia was determined with enzymatic methods (ABX-Horiba). Glycated hemoglobin was determined in EDTA plasma by colorimetry and latex agglutination procedures (ABX-Horiba). In a previously published analysis, the intraclass correlation coefficient for both methods was $0.72(0.67-$ 0.76) for women and $0.91(0.89-0.93)$ for men [7].

Percentiles 5, 10, 25, 50, 75, 90 and 95 of the HbA1c distribution were estimated by 10year age groups (i.e. $35-44,55-54,55-64,65-74)$ and by sex for both the POC and the central laboratory results. Pearson correlations were performed between glycaemia and HbA1c determined with both methods. All statistical analyses were performed with the R Statistical Package (V.3.3.2).

The present study included 895 individuals (53.3\% women; mean age 50 years [standard deviation=10]). Median POC values of HbA1c were slightly higher than the centralized laboratory values $(5.5 \%$ [5.3-5.7] vs. 5.4\% [5.2-5.7], respectively). Table 1 summarizes the main participant characteristics by sex. HbA1c levels obtained by each method increased 
with age in both men and women (Figure 1). The $75^{\text {th }}$ percentile of HbAlc in both men and women was $5.7 \%$, the cut-off point for the diagnosis of prediabetes [1]. When stratified by age, almost half of our sample aged 65 or older had HbAlc values $\geq 5.7 \%$. We observed greater variability in the results from the centralized laboratory, particularly at the low ranges. However, in both men and women the Pearson correlations between HbAlc and fasting glucose were similar with both methods (Figure 2).

\section{Discussion and conclusion}

The present study describes the HbAlc age distribution in a Mediterranean population without a history of diabetes or cardiovascular disease, estimated by central laboratory and by POC testing. The mean HbA1c observed was similar to previously described results in American and Chinese populations $[4,5]$. In addition, Ma et al. described a gradual ageassociated increase in $\mathrm{HbAlc}$ in the Chinese population aged 18 to 99 years [5]. In our population, a high percentage of the population older than 70 years had values indicative of prediabetes. Although this finding should not lead to the prescription of a drug treatment, non-pharmacological approaches including nutritional intervention and lifestyle changes can be applied. Other individual factors and the personal risk of developing diabetes should also be taken into account, especially in older adults [1].

The POC measurement of HbA1c is a relatively recent approach that is gaining users, given its convenience of use. The intraclass correlation coefficients for the comparison of POC with the central laboratory method was fair to good in women and excellent in men [9]. On the one hand, it benefits the patient who obtains integrated care in less time, without requiring a second visit to obtain the results. On the other hand, it offers healthcare providers 
the possibility of timely decisions that improve effectiveness and strengthen the preventive message transmitted to patients $[3,10,11]$.

HbA1c was increased across all age groups, with similar interquartile range in both men and women. The central laboratory and POC techniques yielded similar $\mathrm{HbA} 1 \mathrm{c}$ concentrations. The capillary blood results can be used as reference values in a Mediterranean population with no history of diabetes or cardiovascular disease.

\section{Conflict of interest}

The authors state that they have no conflicts of interest.

\section{Financial support}

This study was financed by Spain's Ministry of Economy and Competitiveness through the Carlos III Health Institute FEDER (CM12/03287, CPII17/00012, and FIS14/00449)

\section{Ethical approval}

Written informed consent was obtained from all participants. The present study was approved by the Clinical Research Ethics Committee of Parc de Salut Mar (CEIC-PSMAR, \#2014/5815/I).

\section{Acknowledgments}


The authors wish to thank Marta Cabañero, Leny Franco, Neus Guday, Montse Peris, Martina Sidera, and Susanna Tello for their contribution to the data collection and management of this project.

\section{Author contributions}

All authors made substantial contributions to study conception and design and to data acquisition or analysis and interpretation, took part in drafting the article or revising it critically for important intellectual content, gave final approval of the version to be published, and agree to be accountable for all aspects of the work.

\section{REFERENCES}

[1] L. Rydén, P.J. Grant, S.D. Anker, C. Berne, F. Cosentino, N. Danchin, C. Deaton, J. Escaned, H.P. Hammes, H. Huikuri, N. Marre, N. Marx, L. Mellbin, J. Ostergren, C. Patrono, P. Seferovic, M.S. Uva, M.R. Taskinen, M. Tendera, J. Tuomilehto, P. Valensi, J.L. Zamorano, ESC Guidelines on diabetes, pre-diabetes, and cardiovascular diseases developed in collaboration with the EASD: the Task Force on diabetes, pre-diabetes, and cardiovascular diseases of the European Society of Cardiology (ESC) and developed in collaboration with the European Association for the Study of Diabetes (EASD), Eur. Heart J. 34(39) (2013) 3035-87. 
[2] I.L. Dubach, E.R. Christ, P. Diem, HbA(1c)-testing: Evaluation of two point-of-care analysers, Prim. Care Diabetes, (2019). pii: S1751-9918(19)30089-0. doi: 10.1016/j.pcd.2019.05.007.

[3] T. Kenealy, G. Herd, S. Musaad, S. Wells, $\operatorname{HbA(1c)~screening~in~the~community:~}$ Lessons for safety and quality management of a point of care programme, Prim. Care Diabetes, 13 (2) (2019) 170-175. doi: 10.1016/j.pcd.2018.11.008.

[4] E. Selvin, M.W. Steffes, H. Zhu, K. Matsushita, L. Wagenknecht, J. Pankow, J. Coresh, F.L. Brancati, Glycated hemoglobin, diabetes, and cardiovascular risk in nondiabetic adults, N. Engl. J. Med. 362(9) (2010) 800-11.

[5] Q. Ma, H. Liu, G. Xiang, W. Shan, W. Xing, Association between glycated hemoglobin A1c levels with age and gender in Chinese adults with no prior diagnosis of diabetes mellitus, Biomed. Rep. 4(6) (2016) 737-740.

[6] C. Giráldez-García, F.J. Sangrós, A. Díaz-Redondo, J. Franch-Nadal, R. Serrano, J. Díez, P. Buil-Cosiales, F.J. García-Soidán, S. Artola, P. Ezkurra, L. Carrillo, J.M. Millaruelo, M. Seguí, J. Martínez-Candela, P. Muñoz, A. Goday, E. Regidor; PREDAPS Study Group, Cardiometabolic Risk Profiles in Patients With Impaired Fasting Glucose and/or Hemoglobin A1c 5.7\% to 6.4\%: Evidence for a Gradient According to Diagnostic Criteria: The PREDAPS Study, Medicine (Baltimore). 94(44) (2015) e1935.

[7] M. Barroso, S. Pérez-Fernández, M.M. Vila, M.D. Zomeño, R. Martí-Lluch, F. Cordon, R. Ramos, R. Elosua, I.R. Degano, M. Fitó, C. Cabezas, G. Salvador, C. Castell, M. Grau M, Validity of a method for the self-screening of cardiovascular risk, Clin Epidemiol. 10 (2018) 549-560.

[8] J.A. Hirst, J.H. McLellan, C.P. Price, E. English, B.G. Feakins, R.J. Stevens, A.J. Farmer, Performance of point-of-care HbA1c test devices: implications for use in clinical 
practice - a systematic review and meta-analysis, Clin Chem Lab Med. 55(2) (2017) 167180.

[9] G. Perinetti G, StaTips Part IV: Selection, interpretation and reporting of the intraclass correlation coefficient, South Eur J Orthod Dentofac Res. 5(1) (2018) 3-5.

[10] A. El-Osta, M. Woringer, E. Pizzo, T. Verhoef, C. Dickie, M.Z. Ni, J.R. Huddy, M. Soljak, G.B. Hanna, A. Majeed, Does use of point-of-care testing improve costeffectiveness of the NHS Health Check programme in the primary care setting? A costminimisation analysis, BMJ Open. 7 (8) (2017) e015494.

[11]L.A. Motta, M.D.S. Shephard, J. Brink, S. Lawson, P. Rheeder, Point-of-care testing improves diabetes management in a primary care clinic in South Africa, Prim Care Diabetes, 11(3) (2017) 248-253. 


\section{FIGURE LEGENDS}

Figure 1. HbA1c percentiles $(5,10,25,50,75,90,95)$ for point-of-care and central laboratory, by age and sex. The black line marks prediabetes cut-off point $(\mathrm{HbA} 1 \mathrm{c}=5.7 \%)$.

Figure 2. Correlation between Hbalc measured with central laboratory and point-of-care methodologies and fasting plasma glucose by sex. 
Table 1. Characteristics of the participants, by sex

\begin{tabular}{|c|c|c|c|}
\hline & $\begin{array}{l}\text { Women } \\
\text { N=479 }\end{array}$ & $\begin{array}{l}\text { Men } \\
\text { N=416 }\end{array}$ & p-value \\
\hline Age, years, mean (SD) & $50(10)$ & $49(10)$ & 0.036 \\
\hline Education, n (\%) & & & 0.135 \\
\hline Less than primary school & $3(0.6)$ & $0(0.0)$ & \\
\hline Primary school & $106(39.7)$ & $84(20.4)$ & \\
\hline Secondary school & $188(39.7)$ & $188(45.7)$ & \\
\hline University & $177(37.3)$ & $139(33.8)$ & \\
\hline Smoking status, $\mathrm{n}(\%)$ & & & $<0.001$ \\
\hline Non smoker & $251(52.6)$ & $155(37.3)$ & \\
\hline Former smoker & $136(28.5)$ & $143(34.5)$ & \\
\hline Current smoker & $90(18.9)$ & $117(28.2)$ & \\
\hline Body mass index, $\mathrm{kg} / \mathrm{m}^{2}$, mean (SD) & $25.8(4.7)$ & $26.9(3.9)$ & $<0.001$ \\
\hline Waist circumference, $\mathrm{cm}$, mean (SD) & $85.6(12.5)$ & $94.8(11.0)$ & $<0.001$ \\
\hline Obesity, n (\%) & $238(49.7)$ & $270(64.9)$ & $<0.001$ \\
\hline Systolic blood pressure, mmHg, mean (SD) & $106(16)$ & $118(15)$ & $<0.001$ \\
\hline Diastolic blood pressure, $\mathrm{mmHg}$, mean (SD) & $71(11)$ & $78(10)$ & $<0.001$ \\
\hline Hypertension, arterial, $\mathrm{n}(\%)$ & $85(17.9)$ & $138(33.6)$ & $<0.001$ \\
\hline Total cholesterol, mmol/l, mean (SD) & $5.38(0.96)$ & $5.46(0.98)$ & 0.229 \\
\hline HDL cholesterol, mmol/1, mean (SD) & $1.55(0.34)$ & $1.32(0.28)$ & $<0.001$ \\
\hline LDL cholesterol, mmol/1, mean (SD) & $3.39(0.82)$ & $3.52(1.01)$ & 0.041 \\
\hline Triglycerides, mmol/l, median [IQR] & $1.84[1.42-2.51]$ & $2.33[1.71-3.18]$ & $<0.001$ \\
\hline Glucose, $\mathrm{mmol} / \mathrm{l}$, mean (SD) & $2.28[2.15-2.46]$ & $2.41[2.28-2.56]$ & $<0.001$ \\
\hline Central laboratory $\mathrm{HbA} 1 \mathrm{c} \mathrm{mmol} / \mathrm{mol}(\%)$, median [IQR] & $5.4[5.3-5.7]$ & $5.4[5.2-5.7]$ & 0.206 \\
\hline POC HbAlc mmol/mol (\%), median [IQR] & $5.5[5.3-5.7]$ & $5.5[5.3-5.7]$ & 0.538 \\
\hline
\end{tabular}

SD: Standard deviation. HDL: High-density lipoprotein. LDL: Low-density lipoprotein. IQR: Interquartile range. POC: Point of care 
Figure 1.

\section{Women}

HbAlc Point-of-care system

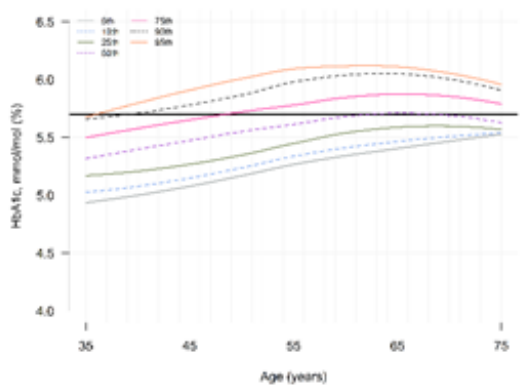

Men

HbAlc Point-of-care system

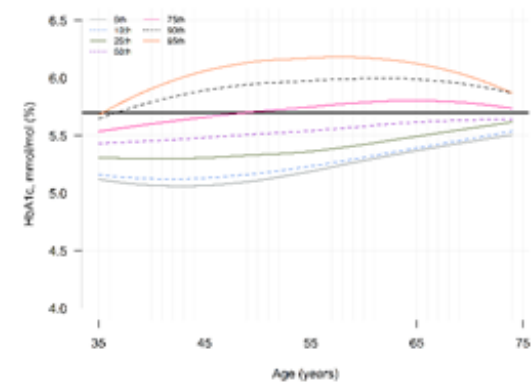

HbAlc Central laboratory

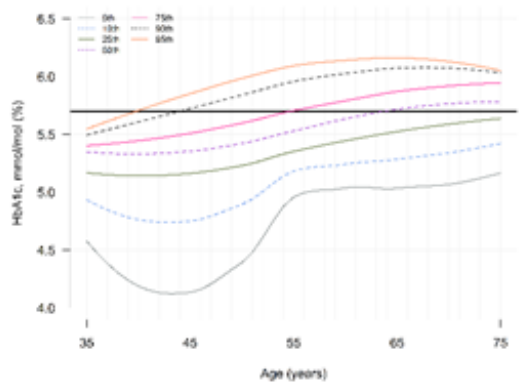

HbAlc Central laboratory

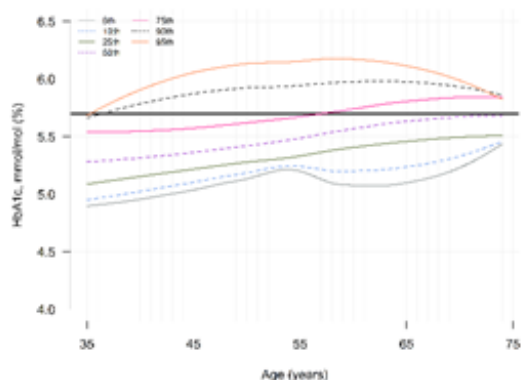


Figure 2.

\section{Women}

HbA1c Point-of-care and glucose

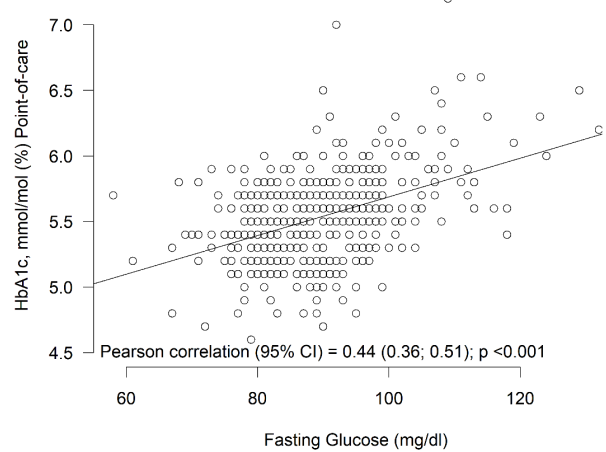

HbA1c Point-of-care and glucose

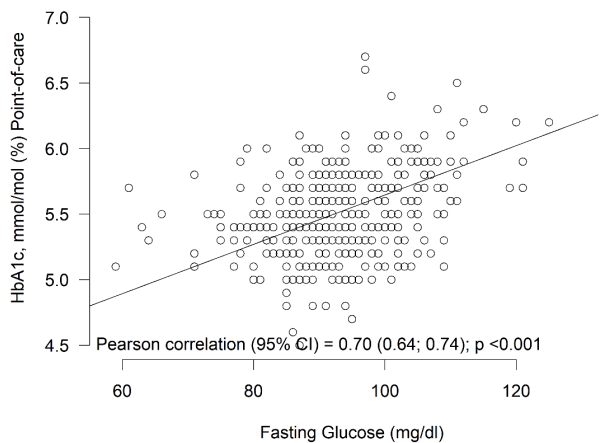

HbA1c Central laboratory and glucose

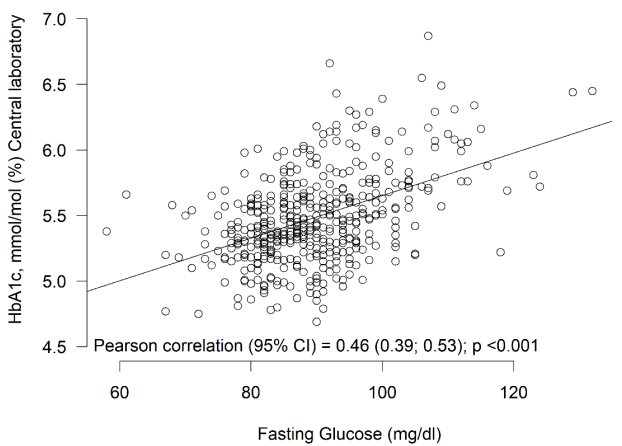

Men

HbA1c Central laboratory and glucose

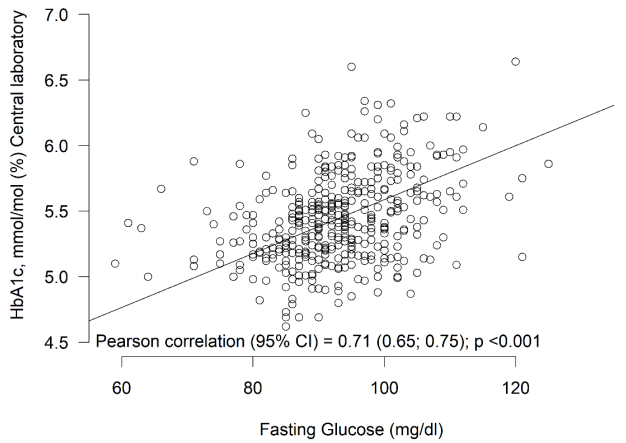

